\title{
Country of origin dan keputusan pembelian konsumen otomotif: Peran nilai terpersepsi sebagai pemediasi
}

\author{
Niko Handoyo ${ }^{a}$, Albert Kriestian Novi Adhi Nugraha ${ }^{b}$ \\ ${ }^{a}$ Fakultas Ekonomika dan Bisnis, Universitas Kristen Satya Wacana, Salatiga, Indonesia; \\ 212015249@student.uksw.edu \\ ${ }^{b}$ Fakultas Ekonomika dan Bisnis, Universitas Kristen Satya Wacana, Salatiga, Indonesia, \\ albert.kriestian@uksw.edu
}

\section{N F O A R T I K E L}

Riwayat Artikel:

Artikel dikirim 02-01-2020

Revisi Artikel 28-03-2020

Artikel diterima 30-03-2020

Keywords:

Country of origin, perceived value, purchase decision, partial least squares

\section{Kata Kunci:}

Country of origin, nilai terpersepsi, keputusan pembelian, partial least squares

\begin{abstract}
A B S T R A C T
This study aims to test the influence of country of origin on car purchase decision through an intervening variable, perceived value. New product faces the big challenge to generate positive consumer responses if it comes from a country associated with past negative stereotype. This research tests a structural model for validating whether country of origin is a relevant variable in consumer purchase decision of high involvement product such as automotive product. A proposed structural model comprises an exogenous variable (country of origin), an intervening variable (perceived value), and endogenous variable (consumer purchase decision). This research applies the non-probability sampling method and purposive sampling technique to collect ninety respondents of Wuling car owners. They filled-out the structured-questionnaires. The data was analyzed by using the structural equation modeling partial least squares (SEM-PLS) which consised of two stages: measurement model and structural model evaluations. The result indicates that perceived value partially mediates the relationship between country of origin and consumer puchase decision.
\end{abstract}

\section{A B S T R A K}

Penelitian ini bertujuan untuk menguji pengaruh country of origin terhadap keputusan pembelian produk otomotif melalui nilai terpersepsi sebagai variabel mediasi. Produk baru yang berasal dari negara dengan stereotif negatif karena pengalaman masa lalu menghadapi tantangan besar untuk dapat memperoleh respon positif dari konsumen. Model struktural diuji untuk memvalidasi apakah country of origin relevan dalam pengambilan keputusan pembelian konsumen terhadap produk dengan keterlibatan tinggi seperti produk otomotif. Model struktural berisi variabel eksogen country of origin, variabel mediasi nilai terpersepsi, dan variabel endogen keputusan pembelian konsumen. Responden penelitian dipilih dengan menggunakan metode non-probability sampling dan teknik purposive sampling. Responden adalah sembilan puluh pemilik dan konsumen dari tiga tipe produk otomotif Wuling. yang terlibat dalam survei dengan mengisi kuesioner terstruktur. Alat analisis data menggunakan structural equation modeling partial least squares (SEM-PLS) yang terdiri dari dua tahap: pengujian model pengukuran dan pengujian model struktural. Hasil penelitian menunjukkan bahwa nilai terpersepsi secara 
parsial memediasi hubungan country of origin dan keputusan pembelian konsumen.

\section{PENDAHULUAN}

Pengambilan keputusan pembelian konsumen selalu menjadi perhatian bagi pemasar produk. Salah satu determinan yang mempengaruhi konsumen dalam memilih produk adalah efek country of origin (COO) atau negara asal produk (Fischer \& Zeugner-Roth, 2017). Produk yang diasosiasikan berasal dari suatu negara akan berdampak pada sikap dan perilaku beli konsumen (Andéhn \& L'Espoir Decosta, 2016). Produk akan memperoleh posisi baik di hadapan konsumen ketika diasosiasikan dengan negara yang memiliki imej positif (Milovan-Ciuta et al., 2019), hal yang sebaliknya terjadi ketika produk diasosiasikan dengan negara yang memiliki imej negatif. Oleh karena itu, efek COO telah menjadi topik yang paling sering dibahas dalam bidang pemasaran internasional (Samiee et al., 2016).

Relevansi efek COO dapat ditemukan dalam perkembangan industri otomotif di Indonesia. Di Indonesia, saat ini produsen Jepang masih menguasai pangsa pasar otomotif di Indonesia. Gaikindo (2020) merilis daftar 10 besar penjualan otomotif di Indonesia (d.h.i. whole sales dan retail sales) periode Jan-Nov 2019 yang menunjukkan sembilan merek otomotif dalam daftar tersebut berasal dari Jepang (lihat Tabel 1). Hasil ini merupakan hasil akumulasi reputasi yang dibangun sehingga produk otomotif Jepang dikenal sebagai produk yang reliabel, tahan lama, hemat biaya pemeliharaan, dan irit bahan bakar (Rayanti, 2018). Di samping itu, produk otomotif Jepang terkenal karena jaringan servis, dealer, dan distribusi suku cadang yang lebih luas dibandingkan produk otomotif dari negara lain (Ahimsa, 2019).

Dominasi Jepang dalam industri otomotif Indonesia membuat produk kompetitor harus memberikan nilai lebih bagi konsumen untuk memperoleh posisi yang baik di benak konsumen. Nilai terpersepsi (perceived value) menjadi stimulus penting dalam mengevaluasi dan pada akhirnya memutuskan menerima atau tidak menerima tawaran produk yang tersedia bagi konsumen. Saat ini Cina menjadi negara yang terus berusaha memperbaiki imej dari negara penghasil produk harga murah, berkualitas rendah, dan tidak modis menjadi negara penghasil produk berkualitas dan dihargai di pasar dunia (Shepard, 2016). Sebagai contoh, beberapa merek smartphone asal Cina masuk dalam lima besar merek yang menguasai pasar smartphone global (Clinten, 2019). Hal ini menjadi bukti penerimaan produk asal Cina semakin baik di pasar dunia. Tren yang sama diharapkan juga terjadi kategori produk yang lain seperti otomotif. Beberapa merek otomotif Cina mencoba untuk memperoleh pangsa pasar yang berarti di pasar dunia termasuk di pasar Indonesia. Tabel 1 menunjukkan satu merek otomotif asal Cina yaitu Wuling masuk dalam 10 besar penjualan otomotif di Indonesia. Hal ini menunjukkan sinyal positif untuk minat terhadap produk otomotif asal Cina. 
Tabel 1

Penjualan wholesale otomotif di Indonesia periode Januari - November 2019

\begin{tabular}{clrr}
\hline No & \multicolumn{1}{c}{ Merek } & Penjualan (unit) & Pangsa Pasar (\%) \\
\hline 1 & Toyota & 304.344 & 32,4 \\
2 & Daihatsu & 166.429 & 17,7 \\
3 & Honda & 125.034 & 13,3 \\
4 & Mitsubishi Motors & 109.195 & 11,6 \\
5 & Suzuki & 90.267 & 9,6 \\
6 & Mitsubishi Puso & 39.243 & 4,2 \\
7 & Hino & 27.953 & 3,0 \\
8 & Isuzu & 22.702 & 2,4 \\
9 & Wuling & 17.731 & 1,9 \\
10 & Nissan & 11.713 & 1,2 \\
Sumber:(Gaikindo (2020)) & &
\end{tabular}

Meskipun produk otomotif asal Cina mulai mendapatkan perhatian konsumen, namun produsen otomotif asal Cina menghadapi tantangan untuk mengikis stereotif negatif produk otomotif asal Cina dalam hal kualitas (Wahyu, 2018) dan minimnya layanan purna jual (Nayazri, 2017). Untuk mengikis streotif produk otomotif Cina membutuhkan proses waktu karena perbaikan yang dilakukan belum menyeluruh dipahami oleh konsumen (Ikhsan, 2018). Hal ini menunjukkan bahwa efek COO nyata bagi konsumen dalam proses pengambilan keputusan pembelian produk. Fenomena ini mendorong penelitian untuk menguji pengaruh anteseden efek COO terhadap keputusan konsumen dalam membeli produk otomotif dengan nilai terpersepsi sebagai variabel mediasi. Produk otomotif termasuk dalam kategori dengan keterlibatan tinggi (high involement product) dengan mempertimbangkan komitmen sumber daya finansial yang besar, terkait dengan self-image, dan diperhadapkan dengan risiko kinerja. Kontribusi studi ini terletak pada pengujian efek $\mathrm{COO}$ pada produk dengan keterlibatan tinggi khususnya pada produk otomotif yang memiliki stereotif COO yang negatif. Studi ini diharapkan memberikan loloh balik kepada produsen otomotif asal Cina tentang relevansi efek $\mathrm{COO}$ dalam meningkatkan nilai terpersepsi yang berdampak pada keputusan konsumen. Hasil penelitian memberikan justifikasi apakah efektifitas pembenahan yang dilakukan produsen otomotif asal Cina (d.hi. peningkatan kualitas dan layanan purna jual) untuk meningkatkan nilai terpersepsi konsumen diintervensi oleh efek COO.

Studi dilakukan pada subyek 90 konsumen mobil asal Cina merek Wuling. Wuling adalah merek otomotif yang diproduksi oleh konsorsium produsen SAIC-GM (General Motors)-Wuling Automobile (SGMW) (Ikhsan, 2018). Wuling mendirikan pabrik pertama di Indonesia tahun 2015 dan secara resmi merilis lini produk pertamanya yaitu Wuling Confero dan Confero S di Indonesia tahun 2017 (Wuling, 2019). 


\section{KAJIAN PUSTAKA DAN PERUMUSAN HIPOTESIS}

\section{Keputusan Pembelian}

Menurut Kotler \& Keller (2016) keputusan pembelian merupakan keputusan seseorang untuk menjadi pengguna tetap sebuah produk. Keputusan pembelian menurut Schiffman \& Kanuk (2007) adalah pemilihan dari dua atau lebih alternatif pilihan keputusan pembelian, artinya bahwa seseorang dapat membuat keputusan dari beberapa alternatif pilihan. Setiadi (2003) menjelaskan bagaimana seseorang dalam mengambil keputusan dalam pembelian suatu produk. Keputusan pembelian yang dilakukan oleh konsumen melalui beberapa tahap yaitu: tahap pengenalan kebutuhan, tahap pencarian informasi, tahap evaluasi alternatif, keputusan pembelian, dan terakhir tahap perilaku setelah pembelian (Gambar 1). Tahap-tahap pengambilan keputusan tersebut dapat digolongkan dalam kategori pengambilan keputusan yang bersifat komplek (complex decision making) yang berlaku dalam situasi pengambilan keputusan pembelian produk dengan keterlibatan tinggi (Assael, 2005). Beberapa contoh produk dengan dengan keterlibatan tinggi seperti produk otomotif, properti, layanan kesehatan, dan produk asuransi.

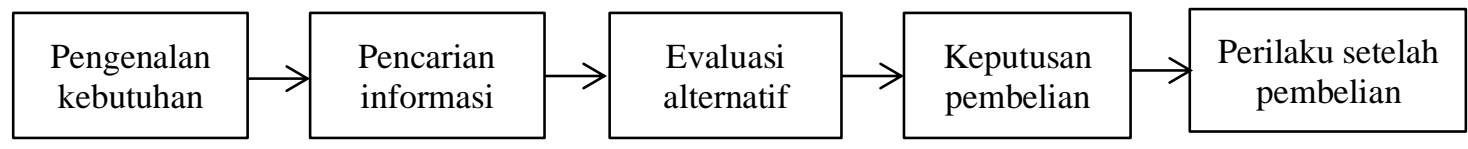

\section{Gambar 1}

Sumber:(Setiadi (2003)

\section{Model Proses Keputusan Pembelian}

Proses keputusan konsumen bermula dari pengenalan kebutuhan yang berlanjut pada pencarian informasi alternatif produk untuk memenuhi kebutuhan tersebut. Selanjutnya, konsumen melakukan evaluasi alternatif produk yang tersedia dengan cara mengekspresikan sikap terhadap alternatif-alternatif yang dipertimbangkan. Sikap adalah respon evaluatif dalam bentuk penilaian suka atau tidak suka terhadap perilaku tertentu (Cesareo \& Pastore, 2014). Penilaian tersebut didasarkan pada karakteristik yang melekat pada produk. Informasi yang dapat dikumpulkan mengenai produk dijadikan dasar konsumen dalam mengevaluasi produk. Persepsi terhadap informasi produk dapat berbeda antar konsumen. Berdasarkan persepsi ini konsumen akan memiliki suatu pandangan tertentu mengenai produk tersebut bisa berupa hal positif maupun negatif (Nursaman et al., 2015).

Salah satu informasi yang digunakan dalam evaluasi produk adalah informasi tentang negara asal produk (country of origin) (Samiee, 2010). Suatu negara dipersepsikan mempunyai reputasi yang eksklusif atas suatu produk tertentu (Krisjanti, 2017). Di negara berkembang seperti Indonesia, masyarakat cenderung lebih memilih produk dari negara maju karena masyarakat lebih percaya dengan kualitas produk tersebut. Hal berbeda dengan masyarakat dari negara maju yang 
cenderung memilih produk lokal karena sudah mengetahui kualitas produk lokal (Setiyaningrum, 2013). Efek country of origin (COO) dapat mempengaruhi nilai terpersepsi (perceived value). Nilai terpersepsi adalah persepsi calon pelanggan dari semua manfaat dan biaya dari penawaran produk (Kotler \& Keller, 2016). Total manfaat pelanggan adalah nilai moneter yang dirasakan dari bundel manfaat ekonomi, fungsional, dan manfaat psikologis yang diharapkan pelanggan dari penawaran produk. Sedangkan biaya pelanggan adalah bundel yang dirasakan dari biaya yang diharapkan konsumen untuk mengevaluasi, memperoleh, menggunakan, dan membuang barang yang sudah digunakan oleh konsumen termasuk biaya moneter, waktu, energi dan biaya psikologis yang dirasakan oleh konsumen. Selanjutnya, nilai terpersepsi konsumen menjadi pertimbangan dalam pengambilan keputusan pembelian konsumen.

\section{Pengaruh Efek COO terhadap Nilai Terpersepsi (Perceived Value) dan Keputusan Pembelian Konsumen}

Kotler \& Keller (2016) mendeskripsikan COO sebagai asosiasi dan kepercayaan mental yang dipicu oleh sebuah negara. Konsumen lebih merasa bahwa produk yang berasal dari negara-negara dengan citra yang positif lebih dihargai dibanding produk yang berasal dari negara yang memiliki citra yang relatif lebih negatif (Suh et al., 2016). Dengan demikian, merek dari negara dengan citra produk yang positif akan lebih dipercayai oleh para konsumen. Yasin et al. (2007) mendefinisikan COO sebagai penilaian konsumen secara umum terhadap negara asal produk berdasarkan keyakinan pada tiga aspek yaitu keyakinan terhadap negara (inovatif, berpendidikan tinggi, reputasi baik, negara maju), keyakinan terhadap orangorang di negara tersebut (tenaga kerja kreatif, tenaga kerja berkualitas tinggi), dan keinginan berinteraksi dengan negara tersebut (negara yang ideal untuk dikunjungi).

Huddleston et al. (2000) menyatakan bahwa efek COO terkait dengan bagaimana konsumen melihat dari negara mana sebuah produk itu berasal. Persepsi konsumen tentang dimana produk itu dibuat umumnya berkaitan dengan tingkat kemajuan teknologi dari negara tersebut. Semakin tinggi tingkat kemajuan teknologi di negara dimana produk itu dibuat maka persepsi konsumen akan kualitas barang dari negara tersebut semakin baik. Oleh karena itu, masyarakat di negara maju lebih memilih produk buatan lokal karena sudah mengetahui kualitas produk dari negaranya berbeda dengan negara berkembang. COO dapat digunakan sebagai sinyal untuk menilai produk (Schiffman \& Kanuk, 2007). Sinyal yang diterima konsumen mengenai negara asal produk dapat mempengaruhi nilai terpersepsi. Penelitian sebelumnya telah menguji pengaruh COO terhadap nilai terpersepsi konsumen (Utomo \& Sanaji, 2018).

Perspektif konsumen mengenai nilai terpersepsi produk dapat dilihat dari negara mana asal produk tersebut. Konsumen menganggap bahwa produk yang dibuat/berasal dari Amerika merupakan produk yang prestisius, kemudian produk 
yang berasal dari Jepang merupakan produk yang inovatif sedangkan produk yang berasal dari Cina merupakan produk yang murah (Putra et al., 2016). Nilai prestisius, inovatif, dan harga murah menjadi sebagian atribut yang membentuk nilai terpersepsi konsumen. Dalam situasi konsumen memiliki pengetahuan terbatas tentang merek yang berasal dari negara tertentu, maka konsumen memanfaatkan fungsi COO sebagai halo effect untuk membentuk nilai terpersepsi konsumen. Di samping itu, konsumen dapat memanfaatkan $\mathrm{COO}$ untuk meringkas keyakinan terhadap merek dan menggunakannya ketika melakukan proses pengambilan keputusan pembelian. Studi sebelumnya telah menguji pengaruh COO pada keputusan pembelian konsumen di berbagai kategori produk (Krisjanti, 2017; Kusumaningtyas et al., 2017; Prasetyo \& Suseno, 2015). Selanjutnya, dengan memperhatikan hubungan COO dengan nilai terpersepsi, maka hipotesis diajukan sebagai berikut:

H1: COO berpengaruh terhadap nilai terpersepsi konsumen.

\section{Pengaruh Efek $C O O$ terhadap Keputusan Pembelian Konsumen}

COO berperan sebagai halo effect ketika konsumen tidak familiar dengan sebuah merek dan menggunakan COO sebagai alat untuk mengambil kesimpulan tentang kualitas merek dari sebuah negara (Knight \& Calantone, 2000) dan kemudian mengambil keputusan pembelian. Sebaliknya, konsumen yang memiliki pengetahuan yang memadai tentang merek produk yang berasal dari sebuah negara maka COO dapat berfungsi sebagai summary cue atau peringkas pengetahuan yang digunakan untuk mengevaluasi merek produk lain dari negara yang sama (Knight \& Calantone, 2000). Jika konsumen merasa puas dengan pengalaman mengonsumsi produk dari COO tertentu, maka dalam pembelian selanjutnya maka konsumen cenderung akan menggunakan $\mathrm{COO}$ sebagai ringkasan pengalaman positif yang dialami dan langsung akan digunakan sebagai penentu keputusan pembelian.

Konsumen menggunakan COO sebagai input/stimulus yang mempengaruhi keputusan pembelian dan mengasosiasikan kualitas dan standar produk dengan $\mathrm{COO}$ (Aynadis, 2014). Peran COO dalam mempengaruhi keputusan pembelian meningkat dalam konteks pembelian produk dengan keterlibatan tinggi (Krupka \& Arežina, 2017). Produk otomotif adalah salah satu contoh produk dengan keterlibatan tinggi (Acharya \& Elliott, 2001) karena memiliki karakteristik pengeluaran finansial yang besar, terkait dengan risiko kinerja, kompleks dalam hal teknologi, serta terkait dengan ego individu (Assael, 2005). Produk otomotif dapat dimasukkan dalam kategori barang mewah karena memberikan manfaat hedonis dan harga yang relatif mahal (Ferrinadewi, 2016). Keputusan pembelian barang mewah seperti produk otomotif umumnya didorong dua alasan utama yaitu ingin memperoleh manfaat emosional/kesenangan dan sebagai ukuran kesuksesan pribadi. (Godey et al., 2012). Berdasarkan hubungan antara COO dan keputusan pembelian, maka hipotesis selanjutnya dinyatakan sebagai berikut: 
H2: COO berpengaruh terhadap keputusan pembelian konsumen.

\section{Pengaruh Nilai Terpersepsi (Perceived Value) terhadap Keputusan Pembelian}

Nilai terpersepsi didefinisikan sebagai penilaian konsumen secara menyeluruh tentang nilai manfaat produk yang dibentuk dari persepsi apa yang diterima secara relatif dibandingkan dengan apa yang harus dikorbankan (Zeithaml, 1988). Nilai terpersepsi diyakini dapat memengaruhi keputusan pembelian (de Medeiros et al., 2016) dan dapat diukur dengan dua pendekatan yaitu satu dimensi atau multi dimensi (Chen \& Chen, 2010). Dalam melakukan sebuah keputusan pembelian, konsumen biasanya mencari informasi dari berbagai sumber tentang produk yang akan dibelinya. Semakin tinggi nilai terpersepsi, semakin tinggi dorongan untuk melakukan keputusan pembelian (Najib et al., 2016). Nilai terpersepsi menjadi salah satu faktor penting dalam mempertahankan daya saing perusahaan dan dimasukkan sebagai pertimbangan dalam menyusun strategi pemasaran (Khasanah, 2015).

Sweeney \& Soutar (2001) berpendapat bahwa dimensi nilai terdiri dari 4 aspek utama: emotional value, yaitu semua manfaat yang berasal dari perasaan atau afektif/emosi positif yang ditimbulkan dari mengkonsumsi suatu produk; social value, yaitu semua manfaat yang didapatkan dari kemampuan produk untuk meningkatkan konsep diri sosial konsumen; quality/performance value, yaitu semua manfaat yang didapatkan dari produk dikarenakan penyusutan biaya jangka pendek dan biaya jangka panjang; serta rice/value for money, yaitu semua manfaat yang diperoleh dari persepsi terhadap kualitas dan kinerja yang diharapkan atas suatu produk. Nilai terpersepsi antar konsumen dapat berbeda-beda. Oleh karena itu pemasar hendaknya memahami pembentukan nilai terpersepsi konsumen produknya dan dapat menyampaikan nilai apa yang dianggap penting oleh konsumen. Diharapkan meningkatnya nilai terpersepsi konsumen dapat mendorong keputusan pembelian konsumen. Berdasarkan pemaparan tersebut maka hipotesis $\mathrm{H} 3$ dirumuskan sebagai berikut:

H3: Nilai terpersepsi berpengaruh terhadap keputusan pembelian konsumen.

Berdasarkan rumusan ketiga hipotesis $\mathrm{H} 1, \mathrm{H} 2$, dan $\mathrm{H} 3$ maka dihasilkan keterhubungan antara variabel $\mathrm{COO}$, nilai terpersepsi, dan keputusan pembelian konsumen. Hal ini memunculkan peran nilai terpersepsi sebagai pemediasi hubungan antara COO dengan keputusan pembelian konsumen. Produk otomotif adalah produk yang masuk dalam kategori high involvement product yang bermakna bahwa pengambilan keputusan membutuhkan pertimbangan sejumlah atribut/faktor mengingatnya pentingnya keputusan pembelian dan risiko sebagai konsekuensi keputusan pembelian produk. Semakin positif COO yang melekat pada produk, semakin positif nilai terpersepsi produk tersebut. Nilai tepersepsi yang dibentuk dari sejumlah atribut/faktor menjadi basis evaluasi konsumen untuk mengambil keputusan pembelian. Selanjutnya, hipotesis $\mathrm{H} 4$ dirumuskan untuk menguji peran nilai terpersepsi sebagai pemediasi sebagai berikut: 
H4: Nilai terpersepsi memediasi hubungan COO terhadap keputusan pembelian konsumen.

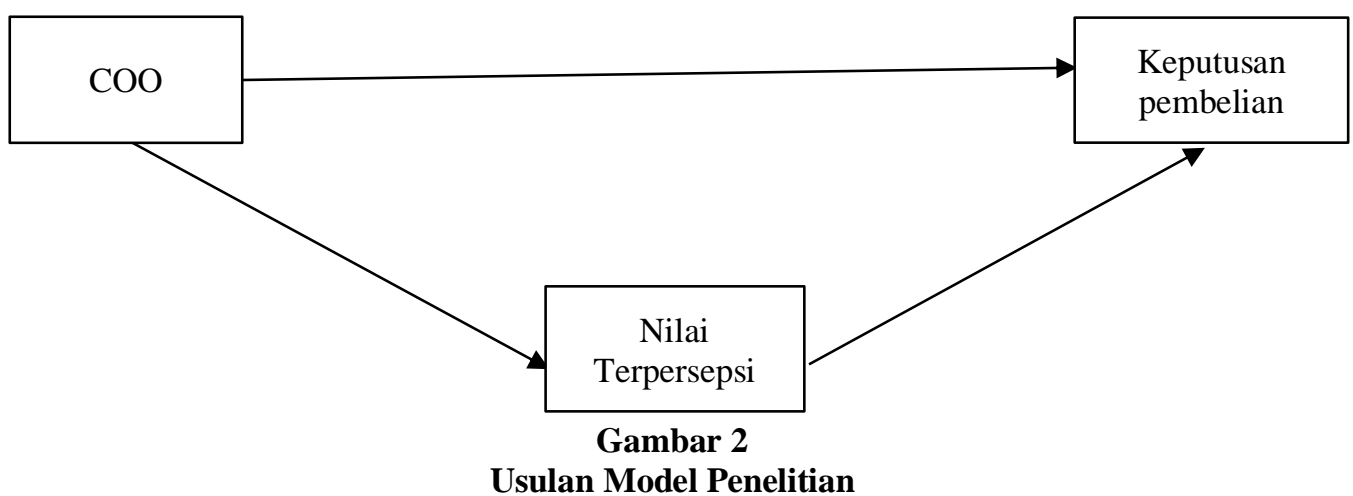

\section{METODE PENELITIAN}

\section{Jenis, Tujuan dan Obyek Penelitian}

Jenis penelitian ini adalah penelitian kuantitatif yang memiliki tujuan eksplanatif. Hal ini berarti penelitian bertujuan untuk menjelaskan fenomena yang terjadi dan memprediksi kejadian dengan ciri adanya hipotesis penelitian yang menetapkan sifat dan arah hubungan antar variabel yang diteliti (Sue \& Ritter, 2012). Objek penelitian adalah suatu sifat dari objek yang digunakan dalam penelitiab untuk dilakukan pengujian dan kemudian memperoleh kesimpulan (Sugiyono, 2010). Objek dalam penelitian ini adalah $\mathrm{COO}$, nilai terpersepsi, dan keputusan pembelian konsumen otomotif merek Wuling.

\section{Pengukuran Variabel}

Penelitian ini menggunakan variabel eksogen $\mathrm{COO}$ yang diukur dengan indikator antara lain daya inovasi, tingkat pendidikan dan penguasaan teknologi tinggi, baik dalam merancang produk otomotif, memiliki reputasi yang baik, merupakan negara maju, tenaga kerja yang kreatif, dan tenaga kerja berkualitas tinggi. Sedangkan variabel endogen (keputusan pembelian) diukur menggunakan indikator antara lain pengenalan kebutuhan, pencarian informasi, evaluasi alternatif, keputusan pembelian, dan perilaku setelah pembelian. Variabel intervening/mediasi nilai terpersepsi diukur dengan indikator emotional value, social value, quality/performance value, dan pricelvalue for money. 
Tabel 2

Pengukuran Variabel

\begin{tabular}{|c|c|c|c|}
\hline Variabel & Definisi & Indikator & Sumber \\
\hline $\begin{array}{l}\text { Country of } \\
\text { Origin } \\
(\mathrm{COO})\end{array}$ & $\begin{array}{l}\text { Country of Origin } \\
\text { adalah identitas yang } \\
\text { ada dalam suatu } \\
\text { produk yang dapat } \\
\text { mempengaruhi } \\
\text { konsumen dalam } \\
\text { mengidentifikasi } \\
\text { darimana asal suatu } \\
\text { produk tersebut } \\
\text { (Moradi \& Zarei, } \\
\text { 2011). }\end{array}$ & $\begin{array}{ll} & \text { Daya inovasi. } \\
\text { - } & \text { Tingkat pendidikan dan } \\
& \text { penguasaan teknologi tinggi. } \\
\text { - } & \text { Baik dalam merancang } \\
& \text { produk otomotif. } \\
\text { - } & \text { Memiliki reputasi yang baik. } \\
- & \text { Merupakan negara maju. } \\
\text { - } & \text { Tenaga kerja yang kreatif. } \\
\text { - } & \text { Tenaga kerja berkualitas } \\
& \text { tinggi. }\end{array}$ & $\begin{array}{l}\text { (Yasin et al., } \\
\text { 2007) }\end{array}$ \\
\hline $\begin{array}{l}\text { Nilai } \\
\text { terpersepsi } \\
\text { (Perceived } \\
\text { value) } \\
\text { ? }\end{array}$ & $\begin{array}{l}\text { Nilai terpersepsi } \\
\text { adalah suatu penilaian } \\
\text { secara menyeluruh } \\
\text { tentang manfaat dari } \\
\text { sebuah produk yang } \\
\text { berdasarkan pada } \\
\text { persepsi setiap } \\
\text { konsumen yang } \\
\text { dikaitkan dengan apa } \\
\text { yang konsumen } \\
\text { peroleh dan apa yang } \\
\text { harus konsumen } \\
\text { berikan (Hellier et al., } \\
\text { 2003). }\end{array}$ & $\begin{array}{ll}\text { - } & \text { Emotional value. } \\
\text { - } & \text { Social value. } \\
\text { - } & \text { Quality/performance value. } \\
\text { - } & \text { Price/value for money. }\end{array}$ & $\begin{array}{l}\text { (Sweeney \& } \\
\text { Soutar, 2001). }\end{array}$ \\
\hline $\begin{array}{l}\text { Keputusan } \\
\text { pembelian }\end{array}$ & $\begin{array}{l}\text { Keputusan pembelian } \\
\text { merupakan keputusan } \\
\text { seseorang untuk } \\
\text { menjadi pengguna } \\
\text { tetap sebuah produk } \\
\text { (Kotler \& Keller, } \\
\text { 2016) }\end{array}$ & $\begin{array}{ll}\text { - } & \text { Pengenalan kebutuhan. } \\
\text { - } & \text { Pencarian informasi. } \\
\text { - } & \text { Evaluasi alternatif. } \\
\text { - } & \text { Keputusan pembelian. } \\
\text { - } & \text { Perilaku setelah pembelian. }\end{array}$ & (Setiadi, 2003). \\
\hline
\end{tabular}

\section{Populasi dan Sampel}

Menurut McClave et al. (2014), populasi adalah sekumpulan unit, biasanya orang, objek, transaksi, atau kejadian, yang ingin kita pelajari. Sedangkan sampel adalah subset unit-unit dari populasi. Populasi dalam penelitian ini adalah konsumen yang membeli produk otomotif Wuling motor. Sampel penelitian ditentukan berdasarkan metode non-probability sampling dengan teknik judgmental sampling dimana sampel terpilih adalah individu yang memiliki kriteria konsumen yang melakukan proses pengambilan keputusan pembelian produk otomotif Wuling. Sampel dalam penelitian ini adalah 90 orang konsumen yang dibagi dalam tiga kelompok berdasarkan tipe produk otomotif Wuling yang dimiliki yaitu Wuling Confero, Wuling Cortez, dan Wuling Allmaz. Jumlah sampel tiap tipe produk otomotif Wuling ditetapkan 30 orang yang memenuhi syarat minimal sampel untuk kebanyakan penelitian (Alwi, 2015). 


\section{Jenis dan Teknik Pengumpulan Data}

Jenis data yang dikumpulkan adalah data primer bersifat kuantitatif yang dikumpulkan dengan metode survey kombinasi datang langsung ke showroom Wuling dan melalui online survey. Responden mengisi kuesioner sendiri (self-administered questionnaire) dan menjawab pertanyaan tentang profil responden beserta tanggapan terhadap item pertanyaan yang berkaitan dengan variabel yang diteliti yaitu $\mathrm{COO}$, nilai terpersepsi, dan keputusan pembelian konsumen. Kuesioner menggunakan skala Likert untuk mengukur tanggapan responden. Skala Likert menggunakan 5 pilihan jawaban yaitu sangat setuju (skor 5), setuju (skor 4), netral/ragu-ragu (3), tidak setuju (skor 2), dan sangat tidak setuju (skor 1).

\section{Teknik Analisis Data}

Model penelitian diuji dengan menggunakan metode analisis kuantitatif dengan teknik analisis Partial Least Squares Structural Equation Modeling (PLSSEM). Pemilihan teknik analisis dengan mempertimbangkan jumlah sampel yang relatif kecil dan jumlah item pengukuran yang cukup banyak. Dalam penelitian ini, aplikasi SmartPLS3 digunakan untuk menilai model pengukuran reflektif yang diajukan. (Hair et al., (2018) memaparkan langkah-langkah yang dibutuhkan sebagai berikut: 1. Menilai outer loadings/factor loadings. Nilai yang direkomendasikan untuk outer loadings di atas 0,708. Untuk keperluan praktis, nilai factor loadings 0,5 dapat dipertimbangkan untuk terus digunakan (Hair et al., 2010); 2. Menilai internal consistency reliability dengan menggunakan composite reliability (CR) dan Cronbach $\alpha$. Nilai CR yang direkomendasikan adalah antara 0,70 hingga 0,90 dan untuk Cronbach $\alpha$ minimal 0,$6 ; 3$. Menilai convergent validity item pengukuran variabel laten yang ada dalam model penelitian. Alat ukur yang digunakan untuk mengukur convergent validity adalah Average Variance Extracted (AVE). Nilai ideal AVE adalah 0,5 ke atas; 4 . Menilai discriminant validity variabel laten yang digunakan dalam model penelitian dengan menggunakan rasio heterotrait-monotrait (HTMT). Nilai ideal rasio HTMT maksimal 0,9.

Setelah penilaian model pengukuran reflektif dilakukan dan hasil disimpulkan memenuhi standar, maka langkah selanjutnya adalah melakukan pengujian model struktural. Standar kriteria penilaian meliputi tiga ukuran yaitu koefisien determinasi $\left(\mathrm{R}^{2}\right)$, nilai akurasi prediksi model jalur Stone-Geisser's $Q^{2}$, dan tingkat signifikansi tiap koefisien jalur yang ada dalam model struktural (Hair et al., 2018).

\section{ANALISIS DAN PEMBAHASAN}

Pengumpulan data dilakukan dengan menggunakan instrumen survei pada konsumen otomotif Wuling. Berdasarkan data yang diperoleh diperoleh profil responden didominasi laki-laki $(96,7 \%)$; berada pada kategori usia 36-45 tahun $(37,78 \%)$, jenis pekerjaan wiraswasta $(36,67 \%)$, dan latar belakang pendidikan sarjana 
(63,33\%). Dalam hal transaksi pembelian, konsumen lebih banyak memilih tipe pembayaran dengan kredit $(57,78 \%)$, melalui lembaga pembiayaan bank $(57,69 \%)$, serta durasi kredit 5-6 tahun $(46,15 \%)$.

Tabel 3

Profil Responden

\begin{tabular}{|c|c|c|c|}
\hline Karakteristik & Kategori & Jumlah & Persentase \\
\hline \multirow[t]{2}{*}{ Jenis Kelamin } & Laki-Laki & 87 & $96,67 \%$ \\
\hline & Perempuan & 3 & $3,33 \%$ \\
\hline \multirow[t]{4}{*}{ Usia } & $15-25$ & 14 & $15,55 \%$ \\
\hline & $26-35$ & 27 & $30,00 \%$ \\
\hline & $36-45$ & 34 & $37,78 \%$ \\
\hline & $46-55$ & 15 & $16,67 \%$ \\
\hline \multirow[t]{3}{*}{ Tipe Mobil } & Almaz & 30 & $33,33 \%$ \\
\hline & Cortez & 30 & $33,33 \%$ \\
\hline & Confero & 30 & $33,33 \%$ \\
\hline \multirow[t]{4}{*}{ Pekerjaan } & Pegawai Swasta & 36 & $40 \%$ \\
\hline & PNS & 12 & $13,33 \%$ \\
\hline & Wiraswasta & 33 & $36,67 \%$ \\
\hline & Lain-Lain & 9 & $10 \%$ \\
\hline \multirow[t]{5}{*}{ Pendidikan Terakhir } & SMP & 2 & $2,22 \%$ \\
\hline & SMA & 20 & $22,22 \%$ \\
\hline & $\mathrm{S} 1$ & 57 & $63,33 \%$ \\
\hline & $\mathrm{S} 2$ & 9 & $10 \%$ \\
\hline & $\mathrm{S} 3$ & 2 & $2,22 \%$ \\
\hline \multirow[t]{2}{*}{ Cara Pembelian } & Cash & 38 & $42,22 \%$ \\
\hline & Kredit & 52 & $57,78 \%$ \\
\hline \multirow[t]{3}{*}{ Lembaga Pembiayaan } & Bank & 30 & $57,69 \%$ \\
\hline & Perusahaan Leasing & 20 & $38,46 \%$ \\
\hline & Lain-lain & 2 & $4,85 \%$ \\
\hline \multirow[t]{3}{*}{ Durasi Pembiayaan } & 1-2 Tahun & 7 & $13,46 \%$ \\
\hline & 3-4 Tahun & 21 & $40,48 \%$ \\
\hline & 5-6 Tahun & 24 & $46,15 \%$ \\
\hline
\end{tabular}

Sumber: Data primer diolah (2019)

\section{Penilaian Pengukuran Model Reflektif}

Langkah pertama dalam penilaian alat ukur variabel adalah dengan mengevaluasi outer loadings/ factor loadings tiap item yang digunakan untuk mengukur variabel dalam model struktural yang diuji. Hasil evaluasi menunjukkan sembilan item pengukuran yang menghasilkan factor loadings kurang dari 0,5 sehingga dikeluarkan dalam model pengukuran (PV6, KP1-KP5, dan KP7-KP9). Item pengukurangan variabel yang digunakan dalam tahapan selanjutnya sebanyak 26 item dari total 35 item yang dirancang sebelumnya. Secara umum item pengukuran variabel menghasilkan factor loadings dalam rentang nilai 0,543-0,833. Struktur faktor ini secara umum kriteria validitas konvergen terpenuhi meskipun ada beberapa indikator yang memiliki factor loadings di bawah nilai ideal 0,708. Namun untuk keperluan praktis, nilai factor loadings 0,5 ke atas masih dianggap signifikan (Hair et al., 2010). 
Tabel 4

Factor loadings dan cross-loadings untuk model pengukuran reflektif

\begin{tabular}{|c|c|c|c|}
\hline Kode & $\begin{array}{c}\text { Country of } \\
\text { Origin }\end{array}$ & $\begin{array}{l}\text { Keputusan } \\
\text { Konsumen }\end{array}$ & $\begin{array}{c}\text { Nilai } \\
\text { Terpersepsi }\end{array}$ \\
\hline CO1 & 0,694 & 0,471 & 0,451 \\
\hline $\mathrm{CO} 2$ & 0,682 & 0,450 & 0,476 \\
\hline $\mathrm{CO} 3$ & 0,822 & 0,548 & 0,561 \\
\hline $\mathrm{CO} 4$ & 0,723 & 0,497 & 0,455 \\
\hline $\mathrm{CO} 5$ & 0,768 & 0,526 & 0,486 \\
\hline CO6 & 0,725 & 0,511 & 0,423 \\
\hline $\mathrm{CO} 7$ & $\mathbf{0 , 8 3 3}$ & 0,593 & 0,467 \\
\hline CO8 & 0,762 & 0,531 & 0,460 \\
\hline KP10 & 0,576 & 0,779 & 0,672 \\
\hline KP11 & 0,429 & 0,712 & 0,690 \\
\hline KP12 & 0,515 & 0,765 & 0,699 \\
\hline KP13 & 0,346 & 0,673 & 0,700 \\
\hline KP14 & 0,531 & 0,696 & 0,587 \\
\hline KP15 & 0,477 & 0,758 & 0,719 \\
\hline KP16 & 0,482 & 0,686 & 0,612 \\
\hline KP6 & 0,603 & 0,694 & 0,527 \\
\hline PV1 & 0,357 & 0,644 & 0,666 \\
\hline PV10 & 0,461 & 0,618 & 0,701 \\
\hline PV11 & 0,518 & 0,581 & $\mathbf{0 , 7 0 3}$ \\
\hline PV2 & 0,314 & 0,534 & 0,561 \\
\hline PV3 & 0,405 & 0,603 & 0,660 \\
\hline PV4 & 0,400 & 0,686 & $\mathbf{0 , 7 2 0}$ \\
\hline PV5 & 0,446 & 0,469 & 0,582 \\
\hline PV7 & 0,365 & 0,474 & 0,543 \\
\hline PV8 & 0,395 & 0,546 & 0,613 \\
\hline PV9 & 0,435 & 0,712 & 0,757 \\
\hline
\end{tabular}

Sumber: data primer, diolah (2019)

Langkah kedua dalam evaluasi model pengukuran adalah menilai internal consistency reliability melalui ukuran composite reliability (CR) dan Cronbach $\alpha$. Nilai CR dan Cronbach $\alpha$ untuk variabel Keputusan Konsumen, COO, dan nilai terpersepsi berada pada rentang nilai $0,881-0,913$. Rentang nilai tersebut masih memenuhi kriteria nilai yang diharapkan untuk nilai CR antara 0,7 dan 0,9 serta minimal nilai 0,6 untuk Cronbach $\alpha$. Dengan demikian secara umum seluruh variabel dalam model dinilai reliabel. 
Tabel 5

Reliabilitas dan Korelasi Antar Variabel

\begin{tabular}{lcccccc}
\hline \multicolumn{7}{c}{ Korelasi Antar Variabel } \\
\hline & $\begin{array}{c}\text { Cronbach's } \\
\text { Alpha }\end{array}$ & $\begin{array}{c}\text { Composite } \\
\text { Reliability }\end{array}$ & $\begin{array}{c}\text { Average } \\
\text { Variance } \\
\text { Extracted } \\
\text { (AVE) }\end{array}$ & $\begin{array}{c}\text { Country } \\
\text { of } \\
\text { Origin }\end{array}$ & $\begin{array}{c}\text { Keputusan } \\
\text { Konsumen }\end{array}$ & $\begin{array}{c}\text { Nilai } \\
\text { Terpersepsi }\end{array}$ \\
\hline Country of Origin & 0,913 & 0,913 & 0,567 & 1,000 & & \\
Keputusan Konsumen & 0,895 & 0,896 & 0,521 & 0,687 & 1,000 & \\
Nilai Terpersepsi & 0,881 & 0,881 & 0,428 & 0,628 & 0,903 & 1,000 \\
\hline
\end{tabular}

Sumber: data primer, diolah (2019)

Penilaian convergent validity adalah langkah ketiga untuk menentukan kelayakan model pengukuran variabel. Alat ukur yang digunakan adalah nilai Average Variance Extracted (AVE). Secara umum tiga variabel memiliki nilai AVE di atas nilai yang direkomendasikan yaitu 0,5 kecuali nilai terpersepsi menghasilkan AVE kurang dari 0,5. Meskipun variabel nilai terpersepsi memiliki nilai AVE kurang dari 0,5 namun memiliki nilai CR di atas nilai rekomendasi 0,7. Kondisi ini masih dianggap memadai untuk pemenuhan kriteria convergent validity (Fornell \& Larcker, 1981).

Langkah terakhir evaluasi model pengukuran variabel adalah menilai discriminant validity tiap variabel yang masuk dalam model struktural. Item pengukuran hendaknya hanya mengukur/merefleksikan secara eksklusif hanya satu variabel dan tidak untuk mengukur/merefleksikan variabel lain di dalam model struktural. Alat uji validitas diskriman yang digunakan yaitu rasio heterotraitmonotrait (HTMT) dengan kriteria nilai yang direkomendasikan maksimal 0,9. Berdasarkan Tabel 4, seluruh variabel memenuhi nilai rasio HTMT yang direkomendasikan.

Tabel 6

Uji Validitas Diskriminan dengan Rasio Heterotrait-Monotrait

\begin{tabular}{lrrr}
\hline & $\begin{array}{c}\text { Country } \\
\text { of Origin }\end{array}$ & $\begin{array}{c}\text { Keputusan } \\
\text { Konsumen }\end{array}$ & $\begin{array}{c}\text { Nilai } \\
\text { Terpersepsi }\end{array}$ \\
\hline Country of Origin & & & \\
Keputusan Konsumen & 0,686 & & \\
Nilai Terpersepsi & 0,627 & 0,901 & \\
\hline Sumber: data primer, diolah (2019) & &
\end{tabular}

Secara umum model pengukuran memadai untuk dilanjutkan dalam tahap selanjutnya yaitu penilaian model struktural. Langkah-langkah yang dilakukan meliputi uji koefisien determinasi (R2), nilai prediksi Stone-Geisser's $Q^{2}$, dan tingkat signifikansi tiap koefisien jalur dalam model struktural.

\section{Penilaian Model Struktural}

Dengan menggunakan perangkat lunak SmartPLS3 dihasilkan tiga luaran yang dibutuhkan untuk menilai model struktural yang diusulkan. Gambar 1 menunjukkan hasil koefisien determinasi (R2) yang dihasilkan dari pengaruh COO pada nilai 
terpersepsi $(39,4 \%)$ dan pengaruh $\mathrm{COO}$ pada keputusan pembelian konsumen (84,0\%). Hal ini menunjukkan kemampuan COO menjelaskan variasi nilai berada pada kategori kuat sementara kemampuan COO menjelaskan variasi nilai pada variabel keputusan konsumen berada pada kategori mendekati moderat (Hair et al., 2018).

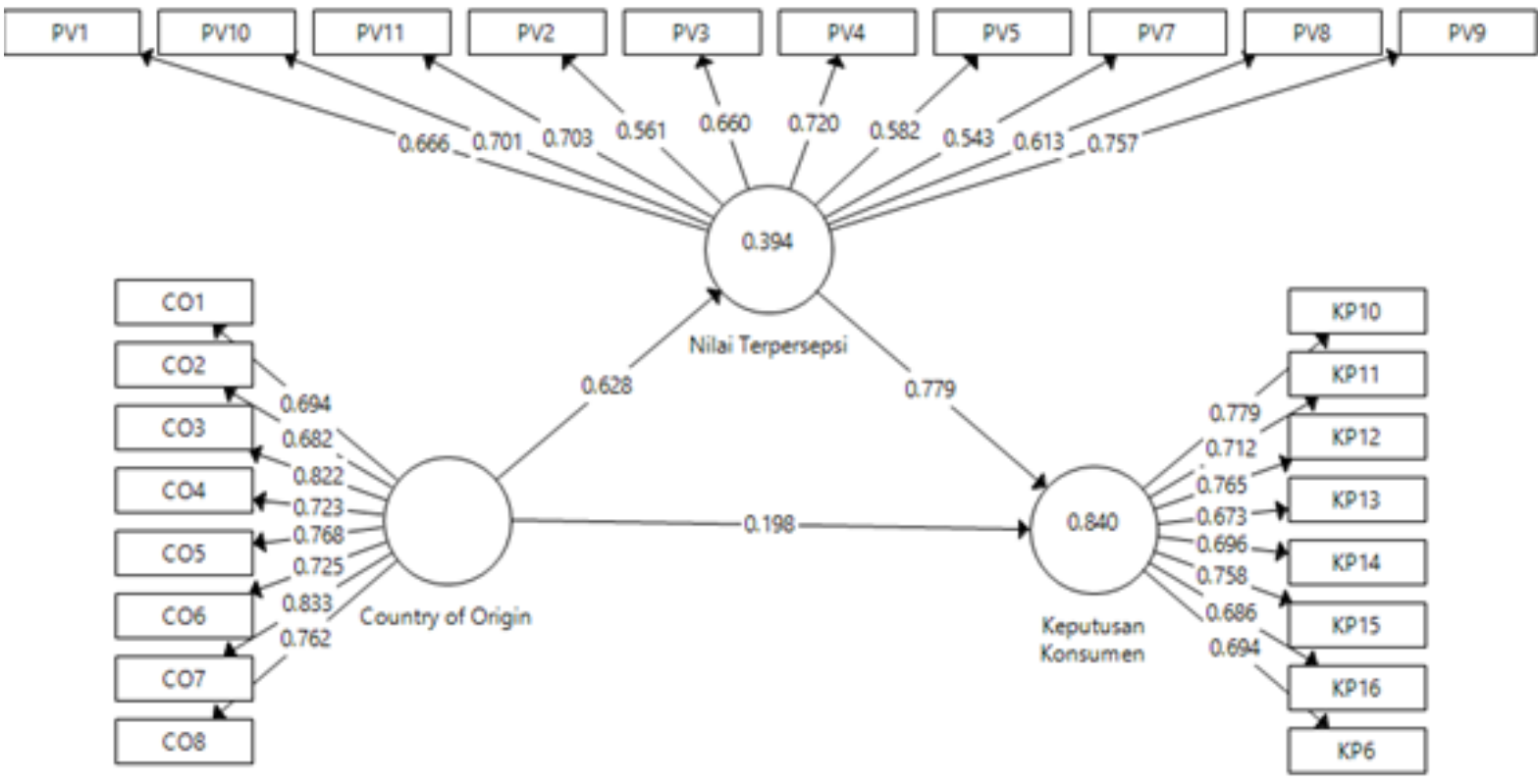

Gambar 3

Model Struktural

Nilai prediksi Stone-Geisser's $Q^{2}$ dihitung dengan menggunakan menu blindfolding procedure yang tersedia dalam aplikasi SmartPLS3. Nilai Stone-Geisser's $Q^{2}$ harus lebih tinggi dari 0 untuk menunjukkan akurasi prediksi dari model struktural. Semakin tinggi nilai $Q^{2}$ semakin tinggi akurasi prediktif model struktural. Nilai Q2 di atas $0,0,25$, dan 0,5 secara berturut-turut menggambarkan relevansi prediktif model struktural dengan menggunakan model jalur PLS berada dalam kategori rendah, sedang, dan tinggi. Berdasarkan Tabel 5 akurasi prediktif model struktural untuk variabel endogen keputusan konsumen berada dalam kategori di sedang $(0,361)$ sedangkan untuk variabel endogennilai terpersepsi berada pada kategori rendah $(0,128)$.

Tabel 7

Nilai Prediksi Stone-Geisser's $Q^{2}$

\begin{tabular}{lccc}
\hline \multicolumn{1}{c}{ Variabel } & SSO & SSE & $\begin{array}{c}\mathbf{Q}^{\mathbf{2}} \\
(=\mathbf{1 - S S E} / \text { SSO })\end{array}$ \\
\hline Country of Origin $(\mathrm{COO})$ & 720,000 & 720.000 & \\
Keputusan Konsumen & 720,000 & 460,118 & 0,361 \\
Nilai Terpersepsi & 900,000 & 784,363 & 0,128 \\
\hline
\end{tabular}

Sumber: data primer, diolah (2019) 
Selanjutnya, hasil uji hipotesis seluruh hubungan kausal di dalam model struktural disajikan dalam Tabel 6. Hasil uji hipotesis menunjukkan COO berpengaruh pada nilai terpersepsi sekaligus juga berpengaruh pada keputusan konsumen. Pengaruh nilai terpersepsi pada keputusan pembelian konsumen dan peran nilai terpersepsi sebagai variabel pemediasi antara COO dan nilai terpersepsi nyata secara statistik. Hal ini menunjukkan bahwa seluruh hipotesis (H1-H4) diterima.

Tabel 8

Uji Hipotesis

\begin{tabular}{cll}
\hline \multicolumn{1}{c}{ Hipotesis } & \multicolumn{1}{c}{ Hasil } & \multicolumn{1}{c}{ Kesimpulan } \\
\hline H1 : COO berpengaruh terhadap nilai terpersepsi & Signifikan (beta $=0,628, p$ & Hipotesis \\
konsumen. & $<0,001)$ & Diterima \\
H2: COO berpengaruh terhadap keputusan & Signifikan (beta $=0,198, p$ & Hipotesis \\
pembelian konsumen. & $<0,05)$ & Diterima \\
H3: Nilai terpersepsi berpengaruh terhadap & Signifikan (beta $=0,779, p$ & Hipotesis \\
keputusan pembelian konsumen. & $<0,001)$ & Diterima \\
H4: Nilai terpersepsi memediasi memediasi & Signifikan (beta $=0,489, p$ & Hipotesis \\
hubungan COO terhadap keputusan & $<0,001)$ & Diterima \\
pembelian konsumen. & & \\
\hline
\end{tabular}

Sumber: data primer, diolah (2019)

Berdasarkan hasil pengujian model pengukuran dan model struktural dapat dilihat peran $\mathrm{COO}$ sebagai variabel penting dalam pengambilan keputusan pembelian konsumen untuk produk otomotif. COO menjadi determinan penting terutama ketika produk terkait dengan stereotif negatif yang masih melekat pada negara asal produk seperti Cina (Nayazri, 2017). Mengubah sikap konsumen bukan merupakan hal yang mudah dan membutuhkan waktu. Hal ini berlaku terutama bagi konsumen yang sudah memiliki pengalaman negatif sebelumnya ketika menggunakan produk asal Cina. Oleh karena itu, produsen otomotif Cina telah melakukan upaya yang serius untuk memperbaiki imej produk yang dihasilkan dengan melakukan berbagai perbaikan kualitas produk, fitur, dan komitmen layanan purna jual produk. Terjadi fenomena di mana produsen otomotif cenderung menawarkan produk yang memberikan nilai lebih relatif dibandingkan dengan biaya (value for money) untuk dapat bersaing dibandingkan pesaingnya dengan cara menambahkan benefit fitur dengan harga tetap atau lebih rendah (Usman, 2019). Di samping itu, strategi yang dilakukan produsen otomotif asal Cina untuk mengikis stereotip kualitas produk asal Cina adalah dengan memberikan garansi produk jangka panjang (Tolok, 2019). Hal ini diperlukan karena konsumen ingin meminimalkan risiko yang harus dihadapi terlebih produk otomotif adalah produk yang membutuhkan pengorbanan finansial yang besar.

Ubahan positif dalam bentuk value for money yang diupayakan produsen otomotif asal Cina tersebut tidak serta-merta segera direspon positif. Sebagai contoh, produsen Wuling memberikan perhatian pada peningkatan jaringan distribusi penjualan namun hal tersebut belum dianggap memadai bagi konsumen. Penilaian konsumen tidak hanya terletak pada kualitas produk namun juga pada jaringan dealer yang luas serta menerapkan konsep 3S yaitu sales, service, spare parts (Wahyu, 2018). 
Hal ini disebabkan karena produk otomotif bukan merupakan produk sekali pakai sehingga pengalaman positif menggunakan produk otomotif perlu ditopang dengan ketersediaan layanan servis dan spare parts yang memadai bagi konsumen. Di samping itu, ubahan positif dalam bentuk fitur-fitur dengan spesifikasi setara bahkan melalui mobil Jepang masih diragukan kualitasnya (Wahyu, 2018). Hal ini menunjukkan nilai terpersepsi sangat dipengaruhi oleh faktor COO. Selain itu, temuan ini menunjukkan peran COO sebagai summary cue bagi konsumen yang telah memiliki pengalaman menggunakan produk asal Cina dan halo effect bagi konsumen yang belum pernah menggunakan produk asal Cina.

Secara umum, produsen produk Cina pada berbagai kategori berupaya memperbaiki imej produk dan mulai memperoleh respon positif di pasar dunia. Beberapa contoh keberhasilan produk Cina ada pada beberapa kategori produk antara lain mobile phone (Shepard, 2016), komputer (Mahardy, 2013) dan otomotif (Usman, 2019). Jika keberhasilan produk Cina tersebut dapat bertahan atau bahkan meningkat secara konsisten, maka hal itu akan menghasilkan efek COO positif yang berpengaruh pada nilai terpersepsi dan keputusan pembelian konsumen terhadap produk asal Cina di pasar dunia. Secara khusus, efek COO relevan dalam proses pengambilan keputusan konsumen ketika produk yang dieveluasi utamanya adalah produk baru (Coskun \& Burnaz, 2016). Wuling adalah merek produk otomotif asal Cina yang tergolong baru karena baru diluncurkan pada tahun 2017 (Mola, 2019).

\section{SIMPULAN, KETERBATASAN, DAN SARAN}

Beberapa simpulan dapat ditarik berdasarkan hasil pengujian hubungan COO, nilai terpersepsi, dan keputusan pembelian konsumen. Pertama, country of origin berpengaruh positif terhadap nilai terpersepsi dan keputusan pembelian konsumen. Hal tersebut menunjukkan bahwa efek COO relevan dalam keputusan pembelian konsumen produk otomotif Wuling asal Cina. Pengaruh positif COO diduga karena Cina mulai meningkatkan imej sebagai negara penghasil produk berkualitas. Hal ini ditunjukkan dengan sejumlah kategori produk yang diposisikan sebagai produk berkualitas yang mencoba merubah stereotif produk asal Cina di masa lalu yang dianggap kurang berkualitas. Kedua, nilai terpersepsi berperan sebagai pemediasi antara COO dan keputusan pembelian konsumen. COO menjadi reference point bagi konsumen dalam mengevaluasi produk. Semakin positif efek COO, maka semakin positif nilai terpersepsi produk di benak konsumen yang pada gilirannya semakin mendorong keputusan pembelian konsumen. Konsumen pada dasarnya mencari nilai terpersepsi yang diperoleh dari penawaran produk. Semakin tinggi nilai terpersepsi membentuk ekspektasi kepuasan yang akan diperoleh dari mengonsumsi produk tersebut. Ketiga, efek COO berperan penting terutama ketika konsumen mengevaluasi produk baru. Produk otomotif Wuling relatif baru masuk ke pasar Indonesia. Hal ini menyebabkan konsumen yang kurang familiar dengan merek tersebut mengaitkan 
informasi COO ketika mengevaluasi nilai produk tersebut. Dalam hal ini terjadi halo effect di kalangan konsumen.

Keterbatasan penelitian muncul seiring dengan berjalannya proses penelitian. Penilaian evaluasi model pengukuran variabel menunjukkan dua kategori penilaian tidak memenuhi nilai ideal yang diharapkan. Beberapa item pertanyaan menghasilkan nilai factor loadings 0,5 ke atas, meskipun nilai factor loadings ideal adalah 0,708 . Di samping itu, nilai AVE variabel nilai terpersepsi belum memenuhi nilai minimal 0,5 sebagai patokan justifikasi convergent validity. Namun dalam kondisi tertentu hasil factor loadings (Hair et al., 2010) dan AVE (Lam, 2012) masih dianggap memadai. Untuk penelitian mendatang dapat dilakukan penelitian dengan ukuran sampel lebih besar. Di samping itu, analisis data tidak menguraikan lebih lanjut perbedaan evaluasi antara konsumen yang sudah memiliki pengalaman membeli dan mengonsumsi produk asal Cina dengan konsumen yang belum memiliki pengalaman tersebut. Jika perbandingan ini dapat dilakukan maka dapat diketahui perbedaan efek COO yang terjadi di antara dua kelompok tersebut

Berdasarkan hasil penelitian dapat ditarik beberapa saran manajerial untuk pemasaran produk dengan keterlibatan tinggi, khususnya untuk produk yang berasal dari negara dengan stereotif $\mathrm{COO}$ yang negatif. Ubahan-ubahan positif dalam hal fitur-fitur produk dan layanan purna jual telah dilakukan oleh Wuling. Namun untuk mengantisipasi keberatan-keberatan calon konsumen akibat stereotif produk Cina, maka produsen otomotif asal Cina dapat terus melakukan pemberian garansi produk jangka panjang. Di samping itu, perusahaan produk otomotif asal Cina dapat terus meningkatkan nilai lebih pada produknya, seperti memiliki komponen produk yang berkualitas, menjadi pionir dalam penawaran fitur-fitur baru yang belum dimiliki oleh produk pesaing. Hal ini telah diterapkan pada produk Wuling tipe Almaz dengan fasilitas Wuling Indonesian Command (WIND). Inovasi fitur-fitur dapat diterapkan pada tipe produk yang lain agar konsumen merasakan nilai terpersepsi yang lebih tinggi ketika menggunakan produk otomotif asal Cina.

Penelitian ini selanjutnya dapat dikembangkan dengan cara membandingkan model struktural pada dua kelompok konsumen, yaitu konsumen yang memiliki dan belum memiliki pengalaman mengonsumsi produk dari COO tertentu; membandingkan model struktural pada dua atau lebih kategori produk yang berbeda dari COO yang sama (contoh: melakukan perbandingan model struktural ketika diterapkan pada produk otomotif dan mobile phone dari Cina); atau membandingkan model struktural antara produk otomotif yang berasal dari COO yang berbeda (contoh: membandingkan model struktural keputusan pembelian konsumen produk buatan Cina dengan produk dari COO negara yang berbeda seperti Jepang dan Korea).

\section{DAFTAR PUSTAKA}

Acharya, C., \& Elliott, G. (2001). An examincation of the effects of 'country-of- 
design' and 'country-of assembly' on quality perceptions and purchase intentions. Australasian Marketing Journal (Amj), 9, 61-75. https://doi.org/10.1016/S1441-3582(01)70167-X

Ahimsa, R. (2019). 5 alasan orang Indonesia lebih suka membeli mobil Jepang. IDN Times. Retrieved from https://www.idntimes.com/automotive/car/rijaluahimsa/alasan-memilih-mobil-c1c2/full

Alwi, I. (2015). Kriteria empirik dalam menentukan ukuran sampel pada pengujian hipotesis statistika dan analisis butir. Formatif: Jurnal Ilmiah Pendidikan MIPA, 2(2), 140-148. https://doi.org/10.30998/formatif.v2i2.95

Andéhn, M., \& L'Espoir Decosta, P. (2016). The variable nature of country-to-brand association and its impact on the strength of the country-of-origin effect. International Marketing Review, 33(6), 851-866. https://doi.org/10.1108/IMR-05-2015-0137

Assael, H. (2005). Consumer Behavior: A Strategic Approach. Boston New York: Houghton Mifflin Company.

Aynadis, Z. (2014). The 'made-in'effect: Effect of country-of-origin on consumers' buying decision of cloths (A case of COO's effect on Mekelle University students). Asian Journal of Technology \& Management Research [ISSN: 2249-0892], 4(01).

Cesareo, L., \& Pastore, A. (2014). Consumers' attitude and behavior towards online music piracy and subscription-based services. Journal of Consumer Marketing, 31(6/7), 515-525. https://doi.org/10.1108/JCM-07-2014-1070

Chen, C.-F., \& Chen, F.-S. (2010). Experience quality, perceived value, satisfaction and behavioral intentions for heritage tourists. Tourism Management, 31(1), 29-35. https://doi.org/https://doi.org/10.1016/j.tourman.2009.02.008

Clinten, B. (2019). Pasar smartphone mulai bergairah, Samsung rajai 5 besar. Kompas.Com. Retrieved from https://tekno.kompas.com/read/2019/11/11/11210017/pasar-smartphonemulai-bergairah-samsung-rajai-5-besar

Coskun, M., \& Burnaz, S. (2016). Exploring the literal effect of COO for a new brand: A conjoint analysis approach. Journal of International Consumer Marketing, 28(2), 106-120. https://doi.org/10.1080/08961530.2015.1135677

de Medeiros, J. F., Ribeiro, J. L. D., \& Cortimiglia, M. N. (2016). Influence of perceived value on purchasing decisions of green products in Brazil. Journal of Cleaner Production, 110, 158-169. https://doi.org/https://doi.org/10.1016/j.jclepro.2015.07.100

Ferrinadewi, E. (2016). Pengaruh nilai-nilai hedonis dan konsep diri terhadap keputusan pembelian dan dampaknya pada loyalitas merek di Surabaya (studi pada pembelian barang mewah). E-Jurnal Manajemen KINERJA, Universitas Narotama, Surabaya, 2(02), 331-336.

Fischer, P. M., \& Zeugner-Roth, K. P. (2017). Disentangling country-of-origin effects: the interplay of product ethnicity, national identity, and consumer ethnocentrism. Marketing Letters, 28(2), 189-204. 
https://doi.org/10.1007/s11002-016-9400-7

Fornell, C., \& Larcker, D. F. (1981). Evaluating structural equation models with unobservable variables and measurement error. Journal of Marketing Research, 18(1), 39. https://doi.org/10.2307/3151312

Gaikindo. (2020). Indonesian automobile industry data. In Gaikindo.or.id. Jakarta.

Godey, B., Pederzoli, D., Aiello, G., Donvito, R., Chan, P., Oh, H., ... Weitz, B. (2012). Brand and country-of-origin effect on consumers' decision to purchase luxury products. Journal of Business Research, 65(10), 1461-1470. https://doi.org/10.1016/j.jbusres.2011.10.012

Hair, J. F., Risher, J. J., Sarstedt, M., \& Ringle, C. M. (2018). When to use and how to report the results of PLS-SEM. European Business Review, 31. https://doi.org/10.1108/EBR-11-2018-0203

Hair, J. F., Tatham, R. L., Anderson, R. E., \& Black, W. (2010). Multivariate data analysis. Pearson Prentice Hall Upper Saddle River, NJ.

Hellier, P. K., Geursen, G. M., Carr, R. A., \& Rickard, J. A. (2003). Customer repurchase intention: A general structural equation model. European Journal of Marketing, 37(11/12), 1762-1800. https://doi.org/10.1108/03090560310495456

Huddleston, P., Good, L. K., \& Stoel, L. (2000). Consumer ethnocentrism, product necessity and quality perceptions of Russian consumers. The International Review of Retail, Distribution and Consumer Research, 10(2), 167-181. https://doi.org/10.1080/095939600342343

Ikhsan, M. (2018). "Kuda hitam" mobil Cina. CNN Indonesia. Retrieved from https://www.cnnindonesia.com/teknologi/20180219175331-385277240/kuda-hitam-mobil-Cina

Khasanah, I. (2015). Analisis pengaruh preferensi merek, persepsi kualitas, dan perceived value terhadap keputusan pembelian sepeda motor Yamaha matik di Semarang. Jurnal Studi Manajemen Organisasi, 12(2), 115-126. https://doi.org/10.14710/jsmo.v12i2.13153

Knight, G. A., \& Calantone, R. J. (2000). A flexible model of consumer countryoforigin perceptions: A cross-cultural investigation. International Marketing Review, 17(2), 127-145. https://doi.org/10.1108/02651330010322615

Kotler, P., \& Keller, K. L. (2016). Marketing management (15th Global ed). England: Pearson.

Krisjanti, W. M. N. (2017). Evaluasi pengaruh country-of-origin, merek, dan harga pada pembelian produk susu import. Kinerja, 11(1), 64-75. https://doi.org/10.24002/kinerja.v11i1.1385

Krupka, Z., \& Arežina, D. (2017). Importance of country-of-origin on different product categories purchase decision. Marketing of Scientific and Research Organizations, 26(4), 35-54. https://doi.org/10.14611/minib.26.12.2017.11

Kusumaningtyas, G. D., Suharyono, S., \& Abdillah, Y. (2017). Pengaruh country of 
origin terhadap persepsi kualitas dan dampaknya pada minat pembelian (Studi pada calon konsumen yang berminat membeli mobil Toyota Avanza di Jakarta). Jurnal Administrasi Bisnis, 43(1), 77-85.

Lam, L. W. (2012). Impact of competitiveness on salespeople's commitment and performance. Journal of Business Research, 65(9), 1328-1334. https://doi.org/10.1016/j.jbusres.2011.10.026

Mahardy, D. (2013). Sukses di Asia, Lenovo targetkan sukses di pasar smartphone AS. Liputan $6 . \quad$ Retrieved from https://www.liputan6.com/tekno/read/598097/sukses-di-asia-lenovotargetkan-sukses-di-pasar-smartphone-as

McClave, J. T., Benson, P. G., Sincich, T., \& Sincich, T. (2014). Statistics for business and economics. Pearson Boston.

Milovan-Ciuta, A. M., Ardelean, V. M., Sahour, S. A., \& Jurca, F. C. (2019). The country of origin influence on the decision to buy wine- A research framework proposal. Ecoforum Journal, 8(1).

Mola, T. (2019). 2 tahun hadir di Indonesia, ini capaian Wuling. Bisnis. Com. Retrieved from https://otomotif.bisnis.com/read/20190711/275/1123020/2-tahun-hadirdi-indonesia-ini-capaian-wuling

Moradi, H., \& Zarei, A. (2011). The impact of brand equity on purchase intention and brand preference-the moderating effects of country of origin image. Australian Journal of Basic Applied Sciences, 5(3), 539-545.

Najib, M. A., Soesanto, H., \& Sukresna, I. (2016). Analisis pengaruh brand awareness dan perceived value terhadap keputusan pembelian (Studi pada konsumen produk deterjen merek BOOM di Kabupaten Bojonegoro). Jurnal Sains Pemasaran Indonesia, 15(1). https://doi.org/10.14710/jspi.v15i01.62\%20$\% 2073$

Nayazri, G. M. (2017). Kumpulan fakta "mobil Cina" Wuling di Indonesia. Kompas.Com. Retrieved from https://otomotif.kompas.com/read/2017/03/13/080200115/kumpulan.fakta.mo bil.Cina.wuling.di.indonesia

Nursaman, E., Sumarwan, U., \& Djohar, S. (2015). Ekuitas merek jasa gerai buahbuahan berdasarkan persepsi konsumen. Jurnal Manajemen \& Agribisnis, 11(2), 89-99. https://doi.org/10.17358/jma.11.2.89-99

Prasetyo, S. H., \& Suseno, Y. D. (2015). Pengaruh perceived value terhadap keputusan pembelian smartphone android dengan word of mouth positif sebagai variabel moderasi. Jurnal Ekonomi Dan Kewirausahaan, 15, 159-166.

Putra, A. S. U., Suharyono, S., \& Mawardi, M. K. (2016). Pengaruh country of origin dan price terhadap keputusan pembelian (Survei terhadap konsumen Xiaomi di Indonesia, Malaysia, Singapura dan Filipina). Jurnal Administrasi Bisnis, 40(2), 192-200.

Rayanti, D. (2018). Mobil Jepang kuat-kuat? Ini faktanya. Detik.Com. Retrieved from https://oto.detik.com/mobil/d-4310043/mobil-jepang-kuat-kuat-ini-faktanya

Samiee, S. (2010). Advancing the country image construct: A commentary essay. 
Journal of Business Research, 63(4), 442-445. https://doi.org/10.1016/j.jbusres.2008.12.012

Samiee, S., Leonidou, L. C., Aykol, B., Stöttinger, B., \& Christodoulides, P. (2016). Fifty years of empirical research on country-of-origin effects on consumer behavior: A meta-analysis. In Rediscovering the Essentiality of Marketing (pp. 505-510). https://doi.org/10.1007/978-3-319-29877-1_104

Schiffman, L. G., \& Kanuk, L. L. (2007). Consumer behavior. Upper Saddle River, NJ.

Setiadi, N. (2003). Perilaku konsumen: Konsep dan implikasi untuk strategi dan penelitian pemasaran. Jakarta: Prenada Media.

Setiyaningrum, A. (2013). Peran dimensi-dimensi country of origin (COO), consumer ethnocentrism, dan keterlibatan produk pada niat beli konsumen terhadap merek global. Sustainable Competitive Advantage (SCA), 3(1).

Shepard, W. (2016). How "made in Cina" became cool. Forbes.

Sue, V. M., \& Ritter, L. A. (2012). Conducting online surveys (2nd ed.). 2nd ed. https://doi.org/10.4135/9781506335186

Sugiyono. (2010). Statistik untuk penelitian kuantitatif. Bandung: Alfabeta.

Suh, Y., Hur, J., \& Davies, G. (2016). Cultural appropriation and the country of origin effect. Journal of Business Research, 69(8), 2721-2730. https://doi.org/https://doi.org/10.1016/j.jbusres.2015.11.007

Sweeney, J. C., \& Soutar, G. N. (2001). Consumer perceived value: The development of a multiple item scale. Journal of Retailing, 77(2), 203-220. https://doi.org/10.1016/S0022-4359(01)00041-0

Tolok, A. D. (2019). Garansi panjang bikin harga jual mobil Cina terjaga. Bisnis.Com. Retrieved from https://otomotif.bisnis.com/read/20190806/275/1133063/garansi-panjangbikin-harga-jual-mobil-Cina-terjaga

Usman, S. (2019). Cina gebrak pasar otomotif Indonesia. Merdeka.Com. Retrieved from https://www.merdeka.com/khas/Cina-gebrak-pasar-otomotifindonesia.html

Utomo, E. A. S., \& Sanaji, S. (2018). Pengaruh country of origin dan persepsi kualitas terhadap persepsi nilai pada produk telepon seluler. BISMA (Bisnis Dan Manajemen), 6(2), 114. https://doi.org/10.26740/bisma.v6n2.p114-121

Wahyu, D. (2018). Ternyata, masih banyak yang ragu kualitas mobil Cina. Liputan6.Com. Retrieved from https://www.liputan6.com/otomotif/read/3419542/ternyata-masih-banyakyang-ragu-kualitas-mobil-cina

Wuling. (2019). Our achievements. Retrieved from Wuling.id website: https://wuling.id/en-milestone

Yasin, N., Noor, N., \& Mohamad, O. (2007). Does image of country-of-origin matter to brand equity? Journal of Product \& Brand Management, 16(1), 38-48. https://doi.org/10.1108/10610420710731142 
Zeithaml, V. A. (1988). Consumer Perceptions of Price, Quality, and Value: A MeansEnd Model and Synthesis of Evidence. Journal of Marketing, 52(3), 2-22. https://doi.org/10.2307/1251446 


\section{LAMPIRAN}

\section{Tabel 9}

Item Pengukuran Variabel

CO1 Cina merupakan negara yang inovatif dalam menghasilkan produk.

$\mathrm{CO} 2$ Cina memiliki tingkat kemajuan teknologi yang tinggi.

$\mathrm{CO} 3$ Cina menghasilkan desain produk yang bagus.

$\mathrm{CO} 4$ Cina adalah negara yang memiliki reputasi baik.

CO5 Cina adalah negara yang memiliki citra sebagai negara maju.

CO6 Cina memiliki produk-produk yang kreatif.

$\mathrm{CO} 7$ Cina memiliki kualitas tenaga kerja yang tinggi.

CO8 Produk buatan Cina dikerjakan dengan teliti.

PV1 Saya menyukai mobil Wuling yang saya miliki.

PV2 Saya bangga menggunakan produk Wuling.

PV3 Produk otomomotif Wuling yang saya miliki memberikan tawaran yang relative lebih baik dibandingkan dengan tawaran-tawaran produk lain didalam pasar.

PV4 Produk Wuling memberikan rasa percaya diri.

PV5 Sudah banyak yang memakai produk otomotif Wuling.

PV6 Mobil Wuling ini memiliki tingkat kinerja yang melampaui jumlah uang yang saya keluarkan.

PV7 Harga mobil Wuling ini sudah fair/adil untuk kinerja yang saya peroleh.

PV8 Saya merasa uang yang saya keluarkan layak dengan apa yang saya peroleh dari produk Wuling.

PV9 Dengan membeli produk Wuling ini saya telah melakukan pembelian yang tepat.

PV10 Produk Wuling memiliki performa yang baik dibanding produk dari merek lain yang sejenis.

PV11 Produk Wuling memilki desain produk yang menarik dibanding produk dari merek lain yang sejenis.

KP1 Saya memakai produk otomotif Wuling untuk kebutuhan transportasi sehari-hari.

KP2 Saya membeli produk otomotif Wuling untuk menambah citra diri saya.

KP3 Saya tidak mendapatkan hambatan dalam memperoleh informasi tentang produk otomotif Wuling.

KP4 Saya mencari infomasi tentang produk otomotif Wuling dari review-review di media sosial.

KP5 Tenaga penjual aktif memberikan informasi tentang produk otomotif Wuling.

KP6 Menurut saya Wuling memiliki nilai prestise yang tingi.

KP7 Harga beli produk otomotif Wuling sesuai dengan kualitasnya.

KP8 Mobil Wuling memiliki perfoma mesin yang baik dibanding produk otomotif sejenis dikelasnya.

KP9 Mobil Wuling memiliki fitur yang lengkap.

KP10 Produk otomotif Wuling memiliki standar kualitas yang tinggi.

KP11 Saya yakin dengan keputusan saya membeli produk otomotif Wuling.

KP12 Saya yakin akan kualitas produk otomotif Wuling.

KP13 Saya membeli produk Wuling atas keinginan saya sendiri.

KP14 Saya akan merekomendasikan merek Wuling ke pihak lain.

KP15 Saya puas dengan keputusan membeli produk otomotif Wuling.

KP16 Saya akan mempertimbangkan untuk membeli produk Wuling yang lain di waktu yang akan datang. 
